\title{
Creating Social Change In a Municipality Using A Total QUALITY MANAGEMENT APPROACH
}

\author{
Birgitta Bergvall-Kåreborn ${ }^{1}$, Bjarne Bergquist ${ }^{2}$, and Bengt Klefsjö ${ }^{2}$ \\ ${ }^{1}$ Social Informatics \\ ${ }^{2}$ Quality \& Environmental Management \\ Luleå University of Technology, SE-97187 Luleå, Sweden \\ Birgitta.bergvall-kareborn@ltu.se; bjarne.bergquist@ltu,se; bengt.klefsjo@ltu.se \\ Corresponding author: Bengt Klefsjö
}

\begin{abstract}
:
This paper describes a joint project started by citizens, trade life and local government of the Swedish municipality of Jokkmokk to create a positive societal development based on the tenets of Total Quality Management. The project had duration of two years, and did also include a parallel effort made in Mansfield in the United Kingdom, although this paper describes the Jokkmokk part of the project. The evaluation was based on surveys and interviews analysed using Soft Systems Methodology. The analysis shows that most respondents thought that the project was successful in changing attitudes of people of Jokkmokk and of creating valuable networks. The project also had an aim to create involvement of ordinary citizens and many activities were addressed to let citizens develop and generate ideas and participate in societal activities and decision-making. The evaluation showed that the leaders and politicians of Jokkmokk were not ready for the used bottom-up approach. The analysis also underlines the importance of communicating the mission and goals of the project. We consider the achievements, due to the short duration of the project, substantial and both the positive and the negative outcomes present valuable lessons from a societal development perspective.
\end{abstract}

Keywords: Bottom-up perspective, Project CIVIC, Societal development, Soft Systems Methodology, TQM.

\section{INTRODUCTION}

This paper describes an effort to create societal change in the Swedish society of Jokkmokk, and in this section, the basis for this project is introduced.

\subsection{JOKKMOKK AND SOCIETAL DEVELOPMENT IN SWEDEN}

In the year 2004, citizens, trade life and local government of Jokkmokk, Sweden, started joint effort aimed to create a positive societal development. Jokkmokk is a comparably small municipality in northern Sweden, in the sense that it only has around 5500 inhabitants (www.bd.lst.se). However, geographically, it is the second-largest Swedish district in size (two thirds the size of the Netherlands), with 0.3 inhabitants per square kilometre, making it one of the most thinly populated areas of the world. Jokkmokk is situated in the Swedish mountain range and four national parks reside within the municipality borders. Much of the livelihood in Jokkmokk has been based on natural resources, including forestry, hydropower generation and reindeer herding amongst the Sámi people. 
Technological progress and structural changes in the society in general, and on the local labour market particularly, has during twenty years continuously meant a drop in Jokkmokk's major branches; the forest and the hydropower industries. The big companies have reduced their staff and at the same time also the public sector has reduced its staff. The result is high unemployment rates and demographic problems. For instance, more than 6,000 people have left Jokkmokk during this transformation process. Hence, to keep the society from perishing, a change of direction was vital for the municipality.

Inspired by a project in Åseda municipality in the south of Sweden, using values, methodologies and tools from Total Quality Management (TQM) to generate societal development, (Fredriksson, 2003, 2004), the municipality of Jokkmokk, together with local businesses and researchers from Luleå University of Technology (in the following text called “the university”), decided to start a similar journey.

The aim of this paper is to portray this journey by describing the approach used in Jokkmokk to create structural changes as well as a first indication of the results of the approach. The project is described in the following section. The data collection method and the results are presented in the following sections. The paper ends with a discussion and some concluding remarks.

\section{PROJECT CIVIC}

\subsection{HOW PROJECT CIVIC WAS CREATED}

In 2004, a group of people, including a researcher from the university, involved in the Åseda study, and two business consultants, met to discuss possibilities to develop Jokkmokk. They were familiar with the Åseda project and believed in the idea of basing a societal development project on values, methodologies and tools taken from TQM.

International partners were obtained from Mansfield in UK and financial support was approved by the European Union. The project was named "Cultural and Industrial Values In Change" (Project CIVIC) and launched in November 2004 and placed under and cosponsored by 'Strukturum', a Jokkmokk-based company with a mission to aid local business development. Project CIVIC was thus based on two pillars; the Jokkmokk case and the Mansfield case. Project CIVIC was accordingly transnational, but this article focuses on the implementation and experiences from Jokkmokk.

The principal aims of Project CIVIC were:

- To change attitudes, both on a personal and an organisational level, that in time should result in

- an increased sense of responsibility among citizens for the development and survival of their community or neighbourhood

- bringing social and community systems, at various levels, together to participate in, influence and develop the processes that contribute to a positive social change

- Develop a broadly established and positive view of the relation between development and change

- including both the consequences of and the possibilities to changes

\footnotetext{
${ }^{1}$ The company Strukturum is co-owned by the municipality, the national power company, the federation of private enterprises and a local bank.
} 
Authors' pre-print copy of paper published in Total Quality Management \& Business Excellence, 2009, Vol20, No. 12, 1375 - 1393.

- Establish a creative foundation that outlines the form of future democratic decisions and cooperation characterised by influence and participation, but also by insight and knowledge of the surrounding world, analysis and joint force of action.

Similar to the Åseda project, Project CIVIC was built on values, methodologies and tools from TQM.

\subsection{TOTAL QUALITY MANAGEMENT}

TQM has been described in various ways, but the description used in Project CIVIC was the one by Hellsten \& Klefsjö (2000), and the project aimed at implementing "a continuously evolving management system consisting of values, methodologies and tools, the aim of which is to increase external and internal customer satisfaction with a reduced amount of resources." Hellsten \& Klefsjö (2000) argue that to establish a culture based on the values related to TQM, the work must all the time be supported by methodologies (i.e. ways of working) such as process management, benchmarking or improvement teams, which, in turn, must be supported by suitable concrete tools, for instance routines, diagrams and matrices, or Ishikawa diagrams (see Figure 1).

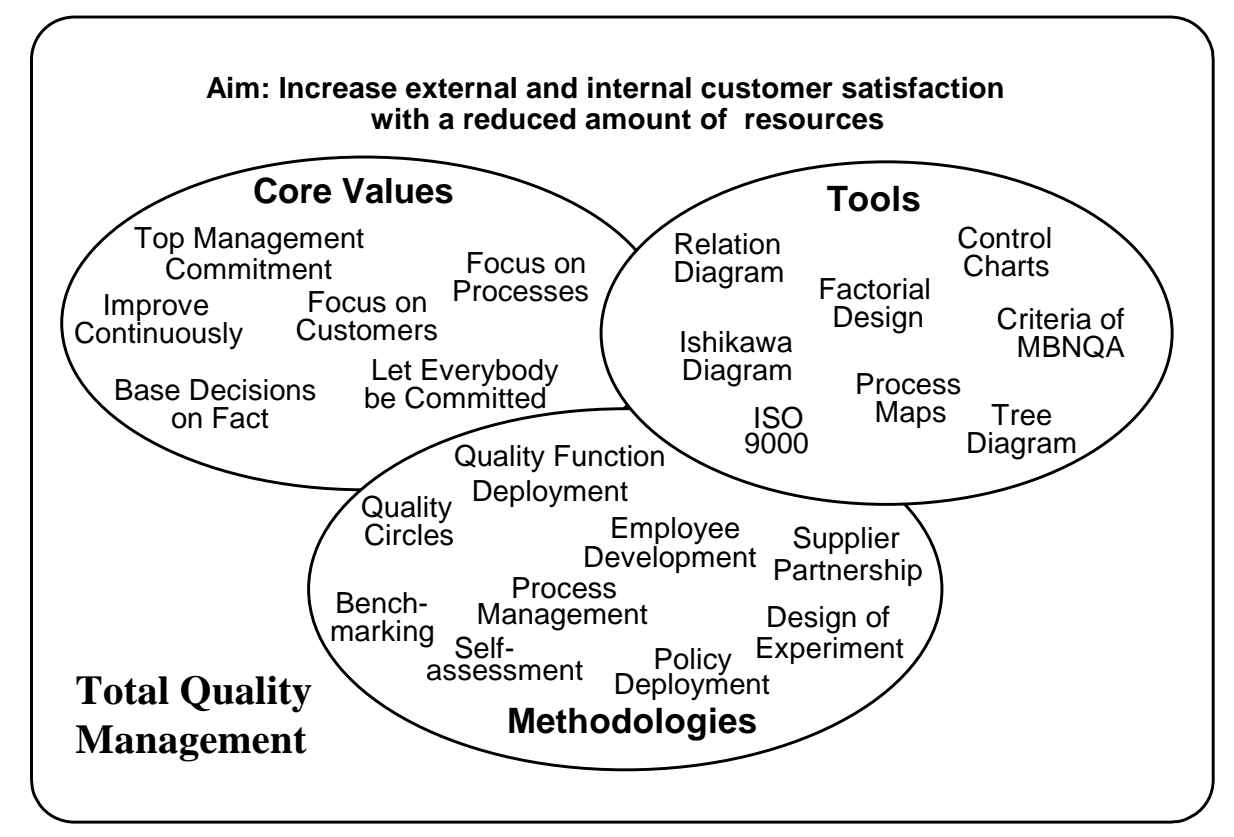

Figure 1. TQM seen as a continuously evolving management system consisting of core values, methodologies (sic) and tools. Adapted from Hellsten \& Klefsjö (2000).

The Swedes involved in the initiation of the project also formed a core in the operational team, here called the Project CIVIC Team, which led the Jokkmokk part of Project CIVIC. Having decided a suitable TQM model for the project, the Project CIVIC Team, influenced by the researcher, judged that the probability of success would increase if some basic values would lay the foundation of Project CIVIC. These core values, listed below, originate from Bergman \& Klefsjö (1994) and correspond to sets of values presented by other authors discussing TQM (for instance Oakland, 1993; Sila and Ebrahimpour, 2002) .

- Focus on customers

- Top management commitment

- Let everybody be committed
- Focus on processes

- Improve continuously

- Base decisions on fact 
The core values used in Project CIVIC differed slightly from those in the Åseda project, since the Åseda Project Team chose to work with the thirteen core values used as a base of the criteria for the Swedish Quality Award. For more on Project CIVIC and its use of TQM; see Svensson et al. (2006).

\subsection{SOME PROJECT CIVIC METHODS}

The bottom-up perspective chosen by the Project CIVIC Team meant that the citizens of Jokkmokk were the primary target for involvement. As a result, no strategic documents or framework was set for Project CIVIC from the beginning. Instead, the project and its values were presented and discussed at a variety of meetings in Jokkmokk, ranging from group meetings and visits to workplaces and associations, to public meetings and general discussion forums. The attendees forming the meeting groups had usually been picked by the appointed project leader, who also was one of the initiating consultants.

There was a broad agreement during the meetings on many core values in an abstract sense, but it was also obvious that these values meant different things for different people. The core value "Improve continuously" was consistently illustrated by referral to the four steps of the Plan-Do-Study-Act improvement cycle (Deming, 1993). The steps were explained and it was pointed out that the improvement cycle often had to be passed several times.

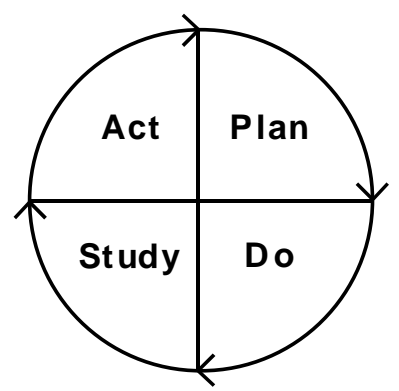

Figure 2. The improvement cycle as presented by Deming (1993). The cycle shows a suggestion of how systematic improvement work might be carried through in four steps.

When the Project CIVIC Team deemed that Project CIVIC had become known and accepted, the next step meant stimulating the creation of development and improvement groups. One year after the start of the project, about twenty improvement groups, with different purposes and levels of activity had started. One of these is a group called "The Jokkmokk Strategic Partnership" (JOSP) including top level Jokkmokk officials and business leaders. The JOSP group was inspired by a similar partnership in Mansfield, the Mansfield Area Strategic Partnership (MASP), and aimed to define several problems that the JOSP group thought were reducing Jokkmokk's abilities to develop. JOSP also aimed to pull the involved organisations to work jointly to overcome these problems, and to contribute to a positive societal change in Jokkmokk. As with all established improvement groups JOSP was also offered support and education in TQM.

There were also competence networks, divided by branches and to outdoor environmental and cleanup groups, as well as event planning groups. Most of these groups had been initiated by the project leader, a man well known by Jokkmokk inhabitants. In all groups, Project CIVIC's core values were introduced by members of the Project CIVIC Team, and the groups were also offered guidance and tutoring in methodologies and tools of continuous improvements.

Project CIVIC Team members also helped with business initiatives such as, for instance, advices for business plans. The team members had often the roles of method specialists and 
coordinators, with the mission to involve as many people and groups as possible and to help establish long-term cooperation between actors.

Parallel with the work of presenting and promoting the project, team members were initiating and coordinating meetings and networks, including several "hands-on" activities to further involve citizens in Project CIVIC. One of the principal undertakings was to rebuild a vacant shop into a local meeting place, called the CIVIC House. This work involved a variety of people, including the retired, adolescents, local entrepreneurs and municipality officials.

About one year into the project, many discussion forums were active and educational initiatives had been taken, some aiming at citizens in general, others directed at particular groups or stakeholders. One of the central activities here was based on Community Development Monitor (CDM) and Community Enterprise Modelling (CEM); see Luczkiw (2007). The aim of CDM is to manage industrial complexity by giving people power to break existing mental models. Through a series of workshops in four groups including more than a hundred people, six topics were discussed using CDM: Global environmental scanning (situational explanations), Community development maturity (stages of community development), Attitudes and values (mental models), Local framework for cooperation and collaboration (community context), Promotion of creativity and innovation (levels of future survival ability), and Building on local resources (stimulating local human and social capital) $)^{2}$.

The four groups that took part in the CDM activities were:

- representatives of trade unions and employers organisations/employers,

- representatives of private, public, non-profit authorities, as well as organisations and groups on local and regional levels involved in developing the local labour market,

- representatives of the citizen group of Jokkmokk including employees, sick-listed employers, unemployed, immigrants, and young people, and,

- adolescents, people between the ages of 15 to 25 intended to provide an ecological perspective of what is happening, locally and globally, what this means, and what needs to be done.

A facilitator joined all meetings to describe the approach, but also to record and condense discussions into formal reports. The reports also formed the base for a public meeting, were participants from the four groups and other citizens met the local politicians. The aim of this meeting was to discuss how the outcomes from the CDM process would influence future strategies, decisions and priorities. It was also debated if and how public participation processes like CDM could be employed in regular community development work as a continuous activity to guarantee best possible practice.

Other learning initiatives include seminars on current leadership, aimed at community leaders, quality seminars focusing on values and tools to promote continuous improvement strategies and on local policy-making and societal changes. Other activities were a project management education directed at people working as project leaders and a seminar series centred on politics and societal development open for all citizens. See Svensson et al. (2006) for more details.

\subsection{WORKING AT DIFFERENT LEVELS}

The Project CIVIC Team considered it important to create a mental picture illustrating core values such as "Everybody's commitment" and other ideas that could be used for communication.

\footnotetext{
${ }^{2}$ See "The CIVIC Guide” by Svensson et al. (2006) for more details.
} 
Therefore, the Project CIVIC Team modelled three levels of society (see Figure 3): Citizens (ordinary people), The Civil Society (members of organisations and associations of all types), and Community Leaders (leaders of both public and private organisations as well as politicians). Citizens are placed in the centre of Figure 3 since the Project CIVIC Team considered citizens an important target of the project, since everybody is a citizen of some kind and since also organisations consist of citizens. The society was modelled into an arrow, to picture a society in progressive change.

\section{Processes and levels of engagement}

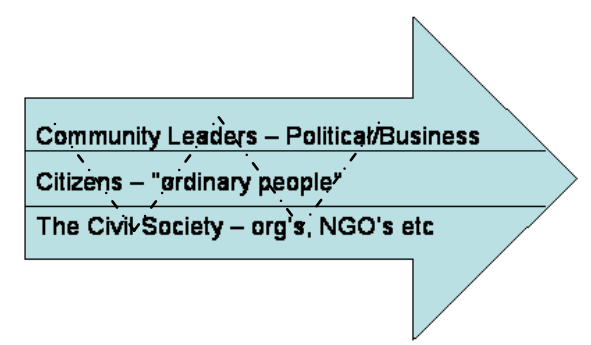

Figure 3. Three levels in a society matching the levels of commitment of the project. The arrowhead indicates that the society as well as the project changes and progresses. The dashdotted lines illustrate that all levels of society are to be mixed.

The three-level model worked as a framework when planning and carrying out Project CIVIC activities. Furthermore, it formed a starting point for prioritizing activities; at what level or to what target group the activity should be directed; and, in what way the result should be displayed.

\section{TQM IN A HISTORICAL AND SOCIETAL CONTEXT}

The decision to use Total Quality Management (TQM) in Jokkmokk was largely based on experiences made by an effort to create societal change in the Swedish community of Åseda (Fredriksson, 2003, 2004). This decision needs consideration. Most literature describing implementation of TQM is attributed to an organisational, or even a business context, whereas implementations in non-profit organisations or large systems, such as communities, are rare.

The concept of TQM has had large impact on management for some decades, and organisations all over the world have tried to use TQM to attain increased competitiveness and improved financial results. Successful TQM implementations, manifested by quality award recipients, show, for instance, better financial results than comparable "average companies”; see Hendricks \& Singhal (1999) and Eriksson \& Hansson (2003). TQM failures are also easily found in literature (Allen \& Kilmann, 2001; Cao et al., 2000).

During the last decades, TQM has been employed also in public and non-profit organisations. The choice to apply TQM in non-business organisations may be based on that many believe private organisations to be more efficient. The increased interest in TQM by non-business type organisations and the adoption of TQM values in these sectors can also be illustrated by 
the establishment of many quality awards in many countries, where non-business applicants are accepted (Chuan \& Soon, 2000; Eriksson, 2002). Some recipients of the Swedish Quality Award, such as Älta School outside Stockholm and the Lung Medical Division of Linköping University Hospital are examples of this trend.

There are also a few examples of TQM applications in governmental organisations, states and municipalities. An early example from 1983 is the city of Madison, WI., in which citizens pulled together in quality efforts, when national funding cuts as well as demographic trends had put the society in difficult situation. Although visible results of the efforts were few after eight years and many problems remained to be solved (as lack of involvement and commitment and difficult organisational problems), the effort was still considered a success. (Box et al., 1991)

Another example is the work in the community of Tacoma, WA. started by volunteers from the Deming Institute in 1996. In the Tacoma project, residents worked with concepts from TQM, and collaboration across traditional community boundaries was a key. The Tacoma example showed that it was possible to channel and boost voluntary improvement activities through the TQM framework, but that several problems needed to be handled differently. For instance, the customer precept has to be reconsidered and common organisational information channels where not present in a societal context. (Jaques, 1999)

\subsection{THE “PROGRESSIVE ÅSEDA” PROJECT}

Åseda, a small community in Southern Sweden with about 2,600 inhabitants suffered from a decrease in population in the middle of the 1990:s. The local industry had difficulties in finding competent personnel since people were reluctant to move to Åseda. Representatives of the local business life, who were used to working with TQM, believed that the TQM ideas could be transferred to a community setting. In 1996, the business representatives therefore initiated a project titled "Progressive Åseda" based on TQM and involving citizens, trade life and local government. "Progressive Åseda” took the form of a non-profit organisation, which became the principal foundation for the improvement work. However, the work and the implementation model were adjusted to accommodate for the organisational structure of a voluntary non-profit organisation. (Fredriksson, 2003, 2004).

"Progressive Åseda” led to several positive results, such as increased well-being of the residents, increased collaboration between companies, politicians and citizens, more activities for citizens and work opportunities. However, during the improvement work, the participants also experienced some difficulties. For instance, engaging residents was difficult and there were problems related to communication with politicians (Fredriksson, 2003, 2004). The experiences from "Progressive Åseda" were condensed into a model on how to implement TQM practice in societal improvement work (Fredriksson, 2005).

\section{EVALUATION APPROACH}

Project CIVIC was evaluated following the formative evaluation tradition, where the overarching purpose is to provide a basis for learning, not merely to summarise the project and its results. Trailing both these purposes, the evaluation has used systems thinking as a general framework, with particular focus on a methodology called Soft Systems Methodology (SSM) (Checkland, 1981; Checkland \& Scholes, 1999). SSM is a general methodology for managing social change that builds on systems thinking and advocates holistic thinking. According SSM, the performance of a system or an organisation, is more influenced by the relation between the parts and how well these parts are adapted and support each other, than by the individual performance of parts. SSM follows a learning and participatory approach, 
and has a focus on worldviews, values, and mental models, which together generate an increased understanding of different stakeholder perspectives. SSM is argued to be well suited to evaluation of complex public-service change initiatives (Rose \& Haynes, 1999). The evaluation process as well as SSM is described in Bergvall-Kåreborn (2006).

In order to engage the team members in the evaluation, the external project evaluator attended meetings with the international and national steering committees, including project leaders and project teams on a regular basis. At these meetings, the evaluation plan as well as individual evaluation activities were jointly planned and discussed, and their results presented. The Project CIVIC Team members have also carried out and handed in a self-evaluation of the activities that they have been responsible for.

\subsection{DATA COLLECTION}

During the evaluation, data have been collected from different sources at different times and with different methods. The most important sources of data have been questionnaires; interviews; participation and observations of seminars and project meetings; self-evaluation by the project team members, and formal documents.

\section{Questionnaire}

A growth and development day directed to citizens of Jokkmokk was arranged by Project CIVIC in December 2005. At this event, 200 questionnaires were handed out to visitors. The questionnaires aimed to probe how citizens of Jokkmokk experienced Project CIVIC, as well as Jokkmokk in general. The questionnaire focused on observed changes in the community over the last 1-2 years, the respondents' information of, and commitment to, Project CIVIC, as well as, on important problems facing Jokkmokk. It consisted of 36 questions divided into four sections: background, view of Jokkmokk, of Project CIVIC, and of Jokkmokk's future. 56 people answered. Out of these, 70\% were female and 41\% were between the age of 15-19 and the rest was evenly distributed over the ages 20-64. The high response from young people also shows in the employment status with $41 \%$ being students and $45 \%$ having paid work.

\section{Interviews}

The evaluation of the project also included interviews, mostly using focus groups to stimulate the creation of interaction. Focus groups are especially appropriate for studying peoples' views or attitudes about a particular phenomenon and generate a broader scale of ideas and views compared to one-on-one interviews (Bloor et al., 2001; Wibeck, 2000). Focus groups also create a situation in which participants can validate and discuss each other's perspectives and experiences.

Five focus group interviews and one individual interview were conducted between March and August 2006. Formal group interviews or individual interviews were conducted with the project leader, the Jokkmokk Steering Committee, part of the JOSP group, part of one CDM group, participants from the project management education, as well as a mixed group of people taking part in various Project CIVIC activities.

The focus groups consisted of 3-6 respondents, and altogether 24 people were interviewed. Each interview was about 60 minutes long and all interviews were recorded, transcribed, and analysed using SSM. Besides these formal interviews, informal talks took place with the Jokkmokk project leader and project team throughout the project.

\section{RESULTS}

In this section, the general results from the questionnaire and the interviews are presented. 


\subsection{QUESTIONNAIRE}

The questionnaire was subdivided between expectation and experience related questions and beliefs related to Project CIVIC and Jokkmokk municipality. The answers are related to the current outlook of Project CIVIC and Jokkmokk, as well as with the future expectations.

\section{Jokkmokk and Project CIVIC}

When Project CIVIC had run for one year, most people did not experience any improvements of structural and institutional aspects, such as number of work opportunities, movement of people, cooperation, and establishment of shops and public services. However, on questions related to changes of culture, attitudes and values, between $30-50 \%$ of the respondents stated that they experienced an improvement. This includes knowledge about the outside world, equality and cultural diversity and readiness for change. More improvement processes; increased participation, responsibility, confidence and feeling of pride; and increased probabilities for new entrepreneurs was also observed.

Notable aspects related to the Project CIVIC specific questions were the high level of awareness of and participation in the project, together with the high coherence between the respondent's views and the project's principal aims. Almost $70 \%$ of the respondents were aware of the project. About $60 \%$ answered that the project had had positive effects, and $30 \%$ had already taken part in some activities arranged by Project CIVIC.

There was a strong correspondence between the respondents' hopes and experiences of Project CIVIC and the general aims of the project, as given in the project plan. There is a correlation between what the respondents had answered that they had hoped Project CIVIC would contribute with, and what they had felt that the project had achieved, already one year into the project. The coupling between hopes and results indicate that Project CIVIC had a successful start.

About the Project CIVIC specific activities that the respondents have taken part in, answers indicate that changes related to attitude; commitment, participation, responsibility; and cooperation tend to start at the operational rather than the managerial level for most people.

\section{The future of Jokkmokk}

The respondents regard the declining number of young people and work opportunities, together with the related problem of a decline in trade and industry, business development and growth as the most important problems facing Jokkmokk. These answers did also correlate with the dreams and fear of the respondents. Notable is that half of the respondents thought that it was through cooperation that the problems facing Jokkmokk could be solved.

\subsection{INTERVIEWS}

The interviews had a broad focus and were directed to different groups, and in the following, the answers to selected discussion points, related to the aim of this paper, are summarized.

\section{What is the project about?}

There was a high level of agreement about the purpose of the project among the respondents on an overarching level; the "why" or "result" level. Most respondents answered that the project was about creating involvement, to stimulate and help citizens take part in the societal development, and the majority agreed that Project CIVIC had contributed here. A few respondents also stressed the importance of raising the awareness and knowledge about general trends in society; what is happening and why. Here, the transnational cooperation with Mansfield was but one important stimuli identified by respondents. 


\section{How should the purpose be accomplished?}

Although there was a common view among the respondents about the purpose of Project Civic, they had differing views on how the purpose should be accomplished. Here, two groups could be identified. One group argued that it was important to involve all members of the municipality, from the ordinary citizen to the municipality leaders and politicians, to create viable social change. Because of this, they meant that the project resources should be divided to cover activities on different levels and geared at different stakeholder groups. This group also argued that involvement from already established groups was important since these groups would remain after project had ended. It was also argued that the project needed to start working with positive and engaged people and hope that this work would inspire a wider group to get involved, though it was the unengaged people with a negative attitude that the project wanted to change most of all.

The second group of respondents argued for a focus on the citizens that are not already engaged. Owing to this, they wanted to direct the resources towards activities that would involve and activate citizens that were unsatisfied with their situation and their municipality. Therefore, some of the respondents said that they did not think the project was focused on them, since they already were involved and had a good understanding of the general trends in society.

\section{What has Project CIVIC accomplished and what are your thoughts about these activities?}

All respondents answered that Project CIVIC had contributed positively to Jokkmokk, directly, through activities arranged within the project, and indirectly, by supporting and coordinating existing groups and initiatives. Here, the networking and coordinating function of Project CIVIC was highlighted by many respondents together with creating changes in peoples' attitudes.

Most respondents answered that there had been a positive change in Jokkmokk with stronger commitment and changes in peoples' attitudes over the last years and that Project CIVIC was one contributor to this. However, even if some respondents felt a strong attitude change among ordinary citizens, but were not sure about the degree of attitude changes at other, higher levels. Some people expressed that there had been initiatives before and in parallel with Project CIVIC that they felt also should be given due credit to the change. They stated that Project CIVIC had helped groups and networks integrate themselves and their activities and given extra energy and that this had stimulated organisations to pull in the same direction.

Most respondents said that it was unimportant to separate changes that should be attributed to Project CIVIC from those due to other activities. One respondent stated that when you know one another well and trust others' good intentions, the risk for suspicion decreases. However, a few respondents said that attribution of credit was an important difficulty and that no project should be recognized for things for which they had not clearly and directly contributed to.

The CIVIC house and how it provided a natural place for people to meet was among the more tangible activities stressed by many respondents. Other tangible activities were the improvements of the outdoor environment and arrangements such as lighting the streets in the town; the educational initiatives; and the exchange visits to Mansfield. Almost all respondents talked about the lessons learned through the exchange with people from Mansfield. Several respondents also said that Mansfield was an interesting partner since they wrestled with similar problems as Jokkmokk, even if there were differences.

Members of the JOSP group emphasized that JOSP assists both coordination of activities and knowledge sharing. Looking at knowledge sharing, one respondent said that the JOSP meetings had improved his knowledge about diverse areas and questions and given him a 
more holistic view of the municipality. It also provided him with facts that made it possible for him to enter discussions and change the direction of a debate.

Concerning the networking and coordinating function, some respondents expressed an uncertainty about who would be able and willing to take this role after Project CIVIC had ended. The respondents said that it was not only a question about finding someone that was willing to take the role; it was equally important that these individuals or groups were trusted and allowed to do so.

Many respondents did also state that it was too early in the project to measure results of different activities, and the consequences of the whole project. Most respondents also said that Project CIVIC was a short project, considering its aims. Bearing that in mind, they said that the project did start a process that was becoming visible for many people, but still was invisible for others. They also answered that the visibility of the process was an achievement and that all consequences of this process might not be visible for another 3-5 years.

\section{Weaknesses-Areas of improvements}

The problems related to weaknesses and/or improvements can be clustered into the three groups: project management, leadership, and change. These problems will be briefly discussed, but leadership and change are commented under the same heading since the respondents discussed leadership and change simultaneously.

\section{Project Management}

Most members of the steering group said that the members of this group did not pull in the same direction. They also said that the steering group, on one hand, and the project leader and the Project CIVIC Team, on the other hand, had differing opinions how Project CIVIC was to be run. The view of the steering group did not match the goals of the project application, and they therefore wanted to modify the project, although the project leader and the Project CIVIC Team wanted to stay true to the goals of the application as much as possible. The steering group said that they would have liked a stronger focus on the general citizen and more money available for tangible activities focused on the citizens. Most participants of the steering group also said that their meetings focused on information of actions rather than on planning and decisions. Instead, they wanted the meetings to focus on what was about to happen and on how to accomplish things. The project leader, on the other hand, said that the principal decisions had already been taken and that the project plan quite clearly specified both the "what" and the "how" of the project. He also said that it was important to give the Project CIVIC Team autonomy to decide how to carry out the primary activities, since they were responsible for them. He also said that actions taken by the project team should be based on their particular competences.

Some respondents said that they had expected and hoped for a stronger initiative and support from the university. One respondent said "We do not need people from Stockholm or Luleå to come here and tell us how things are in Jokkmokk - we know how things are. What we do not seem to know is how to create the needed changes." One respondent also stated that the organisations in Jokkmokk had not used the university and the services they provided in the project enough since they feared to test new ideas.

\section{Leadership and Change}

Many respondents participating in various Project CIVIC activities said that they liked to contribute at meetings if their contribution made a difference, but said that this was not often the case. The respondents stated that leaders and politicians often said that they wanted their ideas and commitment, but when they got it, they did not seem to care. These respondents answered that it was of importance that politicians and official leaders attended seminars 
owing to the signals that send. One example was the seminars on politics and societal development, where one of the politicians did not take part 'due to lack of time' but did not feel guilty about this because she/he meant that the meetings were directed towards ordinary citizens and to motivate more people to be engaged in politics.

Further, some respondents were disappointed about the few attendances at open meetings and seminars. Respondents focused on citizens in general said that the project could have been marketed differently, since few people took part in the activities. Despite focus, many respondents talked about lack of time and stressful professional and private lives as general reasons for not attending. A few respondents also said that at some information meetings, the level of the discussion was above their heads and this made topics difficult to understand and the opportunity to create involvement was failed.

Some respondents said that a lot of interesting ideas were generated by the citizens owing to the project. But for these ideas to be realised, municipality officials often had to handle the ideas, and sometimes also politicians. The respondents felt uncertain whether there was a functioning process for this. The respondents said that many good ideas had been generated, but often, the process ended and nothing happened since none took care of the ideas.

Some respondents said that it is impossible to order people to be involved or to have a sense of responsibility, since these things build on mutual trust. The society leaders must trust the citizens enough to give them freedom to act. Conversely, the citizens need to trust that the leaders will allow them this freedom and that their voices will be heard.

\section{6.}

\section{LESSONS LEARNED}

The primary lessons learned are related to TQM seen as a system consisting of values, methodologies, and tools; see Figure 1 . Here, the focus will be on values, since values have been a focal point of the questionnaire as well as of the interviews. There are also many lessons related to general project management. However, since this is not the aim of the paper we only include those we judge as most relevant and closely related to projects such as Project CIVIC.

\subsection{VALUES}

Looking at the six values in Figure 1, two values are clearly relevant to, and noticeable in the project; "Let everybody be committed" and "Top management commitment." These values are emphasized in the questionnaire answers and discussed in the interviews by many respondents. However, indirectly there are also discussions related to continuous improvement, and some of the consequences that appear when we cannot clearly follow or model a process.

\section{The core value "Let everybody be committed"}

Project CIVIC was permeated by the core value "Let everybody be committed," or "Everybody's participation" as the value was expressed in the project. It is, however, also noticeable how different this core value was interpreted by different individuals and groups. Already at the introductory meetings of the project, the discussions indicated that although the core value "everybody's participation" was accepted by most people, the meaning of the value ranged between everybody participating in cleaning up the streets to everybody participating in developing long-term strategies for local labour market transformation. 
Later in the project, this difference in perspectives became more pronounced and two groups could be identified. One group argued that it was important to involve all members of the municipality, from the ordinary citizen to the municipality leaders and politicians, to create sustainable social change. The second group argued that the project should focus on the citizens that are not already engaged in various activities. This difference in perspective strongly affected the project since the members of the steering committee also held one of these two views.

The lesson learned from this is that it is important to talk about the contextual meanings of a core value. This discussion could start at a well-planned and thorough project kick-off where the participants would get to know one another and where the project is clarified and discussed, and then be continued throughout the project. Such a kick-off creates a common vision or view of the project and gives indications about where divergences between participants can be found and, hence, what parts of the project that need to be discussed more fully.

\section{The relation between “Everybody's participation” and “Top management commitment”}

During the interviews, some respondents expressed disappointment about the operationality of the value "everybody's participation". In particular, the respondents in leading positions stated that few regular citizens had attended open meetings and seminars. Others, mainly regular citizens, said that leaders and politicians appeared to lack interest, and that these groups did not engage enough in the project. These statements point to a feeling of distrust from the general citizens that their involvement will be taken seriously and make a difference. They also indicate a sense of "we-and-them" distinction, rather than a "we" feeling, among general citizens as well as people in leading positions in the municipality.

From this we learn that citizens' involvement builds on trust. Many citizens are both willing and happy to participate in development work if they trust their leaders and feel that their involvement makes a difference. However, without this trust, citizens will not act because of suspicions that their voices will be unheard and their suggestions unimplemented. One way to manage this is to make sure that ideas generated at the bottom are taken up by leaders and politicians and brought to live. It is also a reminder of the strong connection between the values "everybody’s participation" and "top management commitment."

\section{Top management commitment}

Relating the value to the shift from top-down leadership to a bottom-up leadership that the project aims to achieve we have also seen that this shift requires changes in peoples' mental models - leaders, politicians as well as citizens. To be successful, these changes need to be equal, if not larger at the top than at the bottom. Everybody needs to redefine his/her own role. Key concepts such as leaders and citizens; involvement; authority and responsibility must be redefined as well. It is easy for leaders to slip into their old leadership style when they become uncertain or pressed, and, it is easy for people, citizens and project members, to forget their authority and responsibility when things are not moving in the direction they had anticipated. In Project CIVIC, this lack of balance between citizens and leaders was noticeable in situations such as when it was decided how well defined the project should be at the start, and whether key concepts and core values ought to be predefined or allowed to change.

From a leadership perspective, it is a delicate balance between guiding people in a particular direction, and pushing too strongly. It also is required that leaders and politicians trust the citizens enough to give them some freedom to act; a difficulty for leaders used to a traditional, strong leadership style. 


\section{The core value "Improve continuously" in a societal context}

Related to peoples' images of leadership is also the question of who should get credit for successes and be held responsible for mistakes. We found that for projects, such as Project CIVIC, which take a holistic view of societal change and work towards becoming integrated in regular activities and networks, it is often difficult to show direct results and to distinguish between what should be considered an activity within Project CIVIC. The direct effects are often related to activities such as building the CIVIC house, although the indirect effects like facilitating changes in peoples' attitudes and awareness are hard to trace to a certain project or initiative. Here we learn that it is important not to be trapped into focusing on processes that are easily measured and modelled at the expense of processes that are considered most important and central to the project's principal ideas.

Further, when it is difficult to relate a result or consequence to a certain project or activity, it also becomes difficult to relate a result or consequence to a certain person or group. Since getting credit often is important, the question of who should take credit for accomplishments should be discussed. This is true for projects and people, but more important, from the perspective of what is beneficiary for social development in the region or municipality in general.

However, acknowledgement is important to most people, whether they are involved on voluntary basis or if it is their profession. There are often many projects trying to accomplish similar things in a society, and these actions often are uncoordinated. However, to have the overview needed to connect related efforts and processes is hard even for a small municipality such as Jokkmokk. The project lacked a plan both for keeping track of activities and changes that Project CIVIC were responsible for, and how to assign credit for various tasks performed. Although it was not considered important to keep record of changes made ${ }^{3}$, a lesson was that some of the problems with creating involvement would have been overcome if credit for changes were acknowledged.

\section{Base decisions on facts}

That the value "Base decisions on facts" was emphasized became evident during meetings held by the Project CIVIC Team, where tools to synthesize information such as the CDM and affinity diagrams were both demonstrated and used. There was, however, less evidence that the use of these tools had spread to meetings not led or facilitated by someone from the Team.

\subsection{METHODOLOGIES AND TOOLS}

Since Project CIVIC was aimed to make ordinary citizens to participate on voluntary basis, the education on TQM methodologies and tools focused on those who readily could be demonstrated and put to use. Brainstorming tools and affinity diagrams in particular were both introduced and used by many groups. Most respondents have talked positively about the educations in general, but none went into detail about if and how the education or these methodologies did change their behaviours. However, the core idea of both systems thinking and TQM points at the importance to focus on the entirety rather than on the parts. Most respondents, both in the questionnaire and the interviews have adhered to the systemic view and realized the importance of relationships between processes and people. Project CIVIC

\footnotetext{
${ }^{3}$ Some members of the Project CIVIC Team thought that whether activities were recognized as Project CIVIC activities and to people working with the project, or if credit was attributed to some other efforts was not as important as that the activities were started and that they did continue after Project CIVIC was ended. Instead they saw Project CIVIC as a lubricant for all societal progress of Jokkmokk during this time.
} 
Authors' pre-print copy of paper published in Total Quality Management \& Business

Excellence, 2009, Vol20, No. 12, 1375 - 1393.

started by describing the values before continuing with methodologies and tools, but because of the limited time available not much time passed between the two phases.

\subsection{GENERAL PROJECT MANAGEMENT LESSONS}

The third set of lessons relate to general project management concerns and have arisen from the participation and observations at seminars and project meetings as well as from the interviews. Even if these findings in no way are new they must be taken seriously, and Project CIVIC confirms their existence - but also their importance.

\section{Individual, organisational and societal change takes time}

Individual, organisational and societal change takes time - usually more than anticipated and planned for. One consequence is that it may be difficult for people involved to see the progresses made. As one respondent put it "You do not appreciate what you have achieved until you are put back into the starting blocks." Owing to this, it is important to document both the initial state and the development. In projects such as Project CIVIC, it is also important to focus on building confidence and raising peoples' self-esteem, and to ensure people that they are not expected to take big steps until they are ready. If possible, it is also beneficial to start working with young people since it is easier to form certain behaviours among people than to change already established ones.

\section{Building new relations and network are important}

The work related to building new relations and networks should start at a kick-off meeting but need to be developed and maintained throughout the project, because, when people get to know and trust each other, this facilitates cooperation and reduces misunderstandings and suspicions. One way to develop these personal relationships is to bring people out of their ordinary context. An additional benefit with creating relationships between people is that these remain after a project has ended. As such, they constitute one enabling factor for continued cooperation.

\section{Start plan for handing over the project early on in the project}

One crucial aspect in projects such as Project CIVIC, where an attitude change process is started but cannot be completed within the duration of the project, is how the change process will be handed over to the citizens and the society. This work need to be started early in the project and plans for the continuation when funding and other external aids are withdrawn need to be made. This is perhaps the most difficult phase of a change process. This is also a concern raised by many respondents, who said that Project CIVIC had initiated a positive development, but feared that this development should end when the project ended. The activities most respondents expect to continue and prosper are the initiatives that are based on existing groups and/or have been integrated into existing businesses.

\section{REFLECTION}

In this section, we try to lift our eyes and reflect on the study concerning the method used. We also reflect on the results of the project and relate them to the project in Åseda. Further we discuss TQM as a base for societal change.

\subsection{REFLECTING ON THE METHOD}

As always, there are some issues that need to be considered. The project had duration of only two years. This meant that the focus of the project was on starting the transformation process 
rather than following it to a stable state. Owing to funding, the evaluation of the project had to be completed when the project ended. This meant that in reality, much of empiric material was obtained as early as one year into the project. Looking at the short duration of the project before the data collection, the conclusion that so many respondents already had noticed differences becomes astounding. The survey respondents were dominated by young people. The high response rate from adolescents is notable since this is a group that generally is said to be hard to reach. Nonetheless, the rather low response rate of 28 percent together with some bias of respondent background makes it hard to draw conclusions of how Jokkmokk citizens in general felt about Jokkmokk and Project CIVIC. However, the responses are similar to the statements of many interviewees, and the answers are thus at least reflections of streams of opinions in Jokkmokk.

\subsection{REFLECTING ON THE RESULTS}

The project stayed true to its goals and ideals from start to end, even under some pressure. It strove to develop a societal innovation system and it had a genuine attempt to involve those close to the changes, the citizens. To keep the goals and ideals has meant to retain the plan of introducing theoretical frameworks for planning, development and reflection, and not to give in to the local norms and be content with only what is asked for. This meant that the project also tried to reach what might have been beyond the visions of some participants. The ambition to involve citizens has meant to dare to leave the process to the citizens and to also leave the responsibility to them, even when this meant that things took longer than predicted or that things took a different direction than planned.

The project also integrated with other existing initiatives, projects and networks and through this tried to change the systems from within rather than as an outside group. This integration was not always easy since it meant that new ideas tried to integrate with, and sometimes change, traditional ways of doing things. In Jokkmokk, this integration was balanced by some independence as well, since the projects were fairly autonomous. This made it possible for the Project CIVIC Team to ask less comfortable questions and to put demands on groups and stakeholders as an independent organisation.

Finally, the project both developed and implemented a societal innovation system that was built on values, methodologies and tools of TQM. Whether the innovation system will be able to handle continuous changes and restructuring, create a broad forming and a collective social responsibility is too early to say. Many signals indicate that the change is in progress. The two most crucial issues for the future are how integrated these values, methodologies and tools have been in peoples thinking and doing, and, whether there will be groups that take over the process now that the project has formally ended.

\subsection{COMPARING PROJECT CIVIC WITH THE ÅSEDA EXAMPLE}

Project CIVIC was started based on the positive results shown by the project "Progressive Åseda"; (Fredriksson, 2003, 2004), and many positive outcomes of the Åseda example are also visible in Jokkmokk. Examples include the increase in collaboration between groups of society and the recognition of more activities such as meetings and other events. Positive experiences from Åseda that was not found in Jokkmokk include an increase in work opportunities. We do hold it unlikely that employment opportunity changes would be visible already one year into the project. Furthermore, such changes in work opportunities could not be isolated to Project CIVIC; but one of several parallel activities in Jokkmokk. 


\subsection{TQM AS A MODEL FOR SOCIETAL CHANGE}

Project CIVIC could in many ways be considered a success, but if the success is due to the choice to base the implementation on the tenets of TQM or on other factors might be discussed. All groups were offered short courses about values, methodologies and tools that often are used under the TQM umbrella and it is undeniable that tools such as affinity diagrams were used. There are, however, few examples of groups or activities that have leaped through several iterations of the improvement cycle, if at all. There is, of course, the element of the premature evaluation, so possibly, given time, more visible examples of continuous improvements would have been visible. TQM in a societal setting has to address a different context than an organisation. The system boundaries and roles are often unclear and cause-and-effect relationships are complex. The ownership of the community improvement aim is not always apparent and the customer connections are often diffuse (Kinney, 1998).

It is our belief that almost as important as the underlying improvement work model is the commitment of the initiators. In this case, the commitment, competence and personal contacts of the project leader did promote the outcome.

\section{GENERAL CONCLUSIONS}

We have described how systems thinking and TQM have been used in the municipality of Jokkmokk to create structural changes in the society. We have also reported on some results, lessons learned, and reflections from these results.

Finally, linking the results to the principal aims of the project, we can conclude that Project CIVIC managed to start a process that was visible for many people in the municipality, a process these people regarded as positive. The project stimulated changes in attitudes, at least on an individual level, that increased the sense of responsibility among citizens for the development and survival of their community or neighbourhood. It did also, to some extent, bring different social and community systems at different levels together, to influence and develop the processes that contribute to a positive societal change. Further, it did start the process of developing a broadly established creative and positive view of the relation between development and change. Among the principal aims that were furthest away from realization was the establishment of a creative foundation that outlined future democratic decisionmaking and cooperation characterised by citizen influence and participation, by insight and knowledge of the world around, analysis and joint forces of action.

\section{ACKNOWLEDGEMENTS}

We would like to acknowledge Ulf Hägglund, Per Olof Lindroth and Magnus Svensson in the Project CIVIC Team. We would also like to thank all citizens of Jokkmokk for support during the evaluation and, not the least; we wish Jokkmokk the very best on the continuing journey. 
Authors' pre-print copy of paper published in Total Quality Management \& Business Excellence, 2009, Vol20, No. 12, 1375 - 1393.

\section{REFERENCES}

Allen, R.S. \& Kilmann, R.H. (2001). The role of the award system for a total quality management based strategy. Journal of Organizational Change 14 (2):110-131.

Bergman, B. \& Klefsjö, B. (1994). Quality from customer needs to customer satisfaction. London: McGraw-Hill Book Co.

Bergvall-Kåreborn, B. (2006). Cultural and Industrial Values in Change. The International Journal of Knowledge, Culture \& Change Management 6:www.CommonGroundPublishing.com.

Bloor, M., Frankland, J., Thomas, M.T. \& Robson, K. (2001). Focus Groups in Social Research: Introducing qualitative methods. London, UK: Sage Publications Ltd.

Box, G.E.P., Joiner, L.W., Rohan, S. \& Sensenbrenne, F.J. (1991). Quality in the community: One city's experience. Quality Progress 24 (5):57-63.

Cao, G., Clarke, S. \& Lehaney, B. (2000). A systematic view of organisational change and TQM. The TQM Magazine 12 (3):189-193.

Checkland, P. B., \& Scholes, J. (1999). Soft Systems Methodology in Action: A 30-Year Retrospective. New York: John Wiley \& Sons.

Checkland, P.B. (1981). Systems Thinking, Systems Practice. New York: John Wiley \& Sons.

Chuan, T.K. \& Soon, L.C. (2000). A detailed trends analysis of national quality awards world-wide. Total Quality Management 11 (8):1065-80.

Deming, W.E. (1993). The New Economics for Industry, Government, Education. Cambridge, Massachusetts: Massachusetts Institute of Technology.

Eriksson, H. (2002). Benefits from TQM for organizational performance. Doctoral Thesis. Division of Quality and Environmental Management, Luleå University of Technology.

Eriksson, H. \& Hansson, J. (2003). The impact of TQM on financial performance. Measuring Business Excellence 7 (1):36-50.

Fredriksson, M. (2003). TQM as a support for societal development - Experiences from a Swedish Community. Total Quality Management \& Business Excellence 14 (2):225233.

Fredriksson, M. (2004). Experienced effects from applying TQM in societal improvement work in a Swedish community. The TQM Magazine 16 (1):6-13.

Fredriksson, M. (2005). A cooperation model for the third sector based on Total Quality Management. Total Quality Management 16 (6):693-706.

Hellsten, U. \& Klefsjö, B. (2000). TQM as a management system consisting of values, techniques and tools. The TQM Magazine 12 (4):238-244.

Hendricks, K. B. \& Singhal, V.R. (1999). The long-run stock price performance of firms with effective TQM programs. Management Science 47 (3):pp. 359-368.

Jaques, M.L. (1999). Applying quality concepts to community issues. Quality Progress 32 (3):49-56.

Kinney, C.F. (1998). Improving community health through collaboration. Quality Progress $31(2): 39-41$.

Luczkiw, G. (2007). [cited 24 January, 2007. Available from http://www.entreplexity.ca/research/index.html.

Oakland, J.S. (1993). Total Quality Management: The route to improving performance. Second edition. Oxford: Butterworth-Heinemann.

Rose, J. \& Haynes, M. (1999). A Soft Systems Approach to the Evaluation of Complex Interventions in the Public Sector. Journal of Applied Management Studies 8 (2):199216.

Sila, L. \& Ebrahimpour, M. (2002). An Investigation of the Total Quality Management Survey Based on Research between 1998-2000. International Journal of Quality and Reliability Management 19 (7):902-970. 
Authors' pre-print copy of paper published in Total Quality Management \& Business

Excellence, 2009, Vol20, No. 12, 1375 - 1393.

Svensson, M., Klefsjö, B., Dowen, S., Dowen, L. \& Hägglund, U. (2006). CIVIC Guide to Quality in the Community. Jokkmokk, Sweden: Project CIVIC, Strukturum.

Wibeck, V. (2000). Fokusgrupper - Om fokuserade gruppintervjuer som undersökningsmetod. Lund, Sweden: Studentlitteratur. 